\title{
Predicting the Movement of Mesoscale Convective Complexes
}

\author{
S. F. CORFIDI, J. H. MerRitT, AND J. M. Fritsch \\ Department of Meteorology, The Pennsylvania State University, University Park, Pennsylvania
}

(Manuscript received 18 January 1995, in final form 28 November 1995)

\begin{abstract}
A procedure for operationally predicting the movement of the mesobeta-scale convective elements responsible for the heavy rain in mesoscale convective complexes is presented. The procedure is based on the well-known concepts that the motion of convective systems can be considered the sum of an advective component, given by the mean motion of the cells composing the system, and a propagation component, defined by the rate and location of new cell formation relative to existing cells. These concepts and the forecast procedure are examined using 103 mesoscale convective systems, 99 of which are mesoscale convective complexes.

It is found that the advective component of the convective systems is well correlated to the mean flow in the cloud layer. Similarly, the propagation component is shown to be directly proportional (but opposite in sign) and well correlated to the speed and direction of the low-level jet. Correlation coefficients between forecast and observed values for the speed and direction of the mesobeta-scale convective elements are 0.80 and 0.78 , respectively. Mean absolute errors of the speed and direction are $2.0 \mathrm{~m} \mathrm{~s}^{-1}$ and $17^{\circ}$. These errors are sufficiently small so that the forecast path of the centroid of the mesobeta-scale elements would be well within the heavy rain swath of the typical mesoscale convective complex.
\end{abstract}

\section{Introduction}

Mesoscale convective complexes (MCCs) (Maddox 1980) are responsible for most of the warm-season rainfall over the Great Plains (Fritsch et al. 1986). They also produce damaging winds and hail, with nearly one-quarter of them resulting in injury or death (Maddox et al. 1986). Moreover, MCCs substantially alter high-altitude wind fields and can be a significant factor in flight safety and efficiency (Fritsch and Maddox 1981; Maddox et al. 1981). Nevertheless, in spite of their substantial contribution to the production of significant weather, these systems are not forecast very well. This is evident from the historically low levels of skill in quantitative precipitation forecasting (QPF) during the warm season (Ramage 1982; Heideman and Fritsch 1988; Funk 1991; Junker et al. 1992; Olson et al. 1995).

The purpose of the present study is to try to increase skill in warm-season QPF by developing a procedure for forecasting MCC movement. The foundation of the procedure rests on the well-known concept that the motion of convective systems can be considered the sum of an advective component, given by the mean motion of the cells composing the system, and a propagation component, defined by the rate and location of new cell

Corresponding author address: Dr. J. M. Fritsch, Department of Meteorology, College of Earth and Mineral Sciences, The Pennsylvania State University, 503 Walker Building, University Park, PA 16802-5013. formation relative to existing cells (Newton and Katz 1958; Newton and Newton 1959; Chappell 1986; Jiang and Scofield 1987). It is hypothesized that 1) the advective component of MCC movement is proportional to the mean flow in the cloud layer $\left(V_{\mathrm{CL}}\right)$ and 2) that the propagation component $\left(V_{\mathrm{PROP}}\right)$ is directly related (but opposite in sign) to the speed and direction of the low-level inflow that feeds new cell development. To explore these hypotheses, we will select parameters indicative of the advective and propagative components, determine empirically if these parameters relate to the observed motion of MCCs, and then use the resulting relationships to forecast the movement of the convective systems.

It is important to note here that since the emphasis of the study is on QPF, the measure of movement of MCCs will not be the cold cloud shield centroid used by Maddox (1980). Rather, we will focus on the radarobserved movement of the mesobeta-scale (Orlanski 1975 ) convective elements (MBEs) that McAnelly and Cotton (1986) have shown are responsible for the heaviest rainfall. Thus, we have constructed a very simple conceptual model (Fig. 1) that shows the MBE movement as the vector sum of the mean flow in the cloud layer and the propagation component. In this model, it is assumed that the low-level jet $\left(V_{\mathrm{LLJ}}\right)$ is a good indicator of the low-level inflow to the convective systems and that $V_{\mathrm{PROP}}$ is equal and opposite to $V_{\mathrm{LLJ}}$. The model therefore implies that 1 ) a greater mean flow in the cloud layer leads to a greater advective component; 2) a stronger low-level jet leads to a stronger 


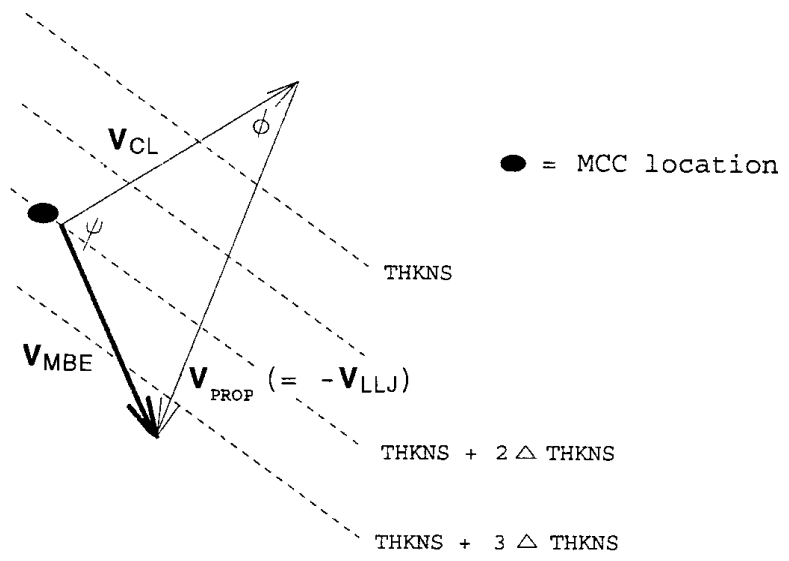

FIG. 1. Conceptual model of MBE movement $\left(V_{\mathrm{MBE}}\right)$ as the vector sum of the mean flow in the cloud layer $\left(V_{\mathrm{CL}}\right)$ and the propagation component $\left(V_{\mathrm{PROP}}\right)$. The magnitude and direction of $V_{\mathrm{PROP}}$ are assumed to be equal and opposite to those of the low-level jet $\left(V_{\mathrm{LLJ}}\right)$ The angles $\phi$ and $\varphi$ are used in (3) and (4) to calculate $V_{\mathrm{MBE}}$ given observed values of $V_{\mathrm{CL}}$ and $V_{\mathrm{LL}}$. Dashed lines (labeled THKNS) indicate a typical relationship of the $850-300-\mathrm{mb}$ thickness pattern to the environmental flow and MBE movement during MCC events.

propagation component toward the source of the inflowing air; and 3 ) the movement of the MBEs ( $\left.V_{\mathrm{MBE}}\right)$ is given by the difference between the mean flow in the cloud layer and the low-level jet; that is,

$$
V_{\mathrm{MBE}}=V_{\mathrm{CL}}-V_{\mathrm{LLJ}} \text {. }
$$

This simple model will be used as a framework upon which to test our hypotheses.

Section 2 describes the data and methods used in the empirical analysis, and section 3 presents the results. A brief summary with concluding remarks is given in section 4.

\section{Data and methodology}

An empirical approach requires, of course, a sizable sample of events. To this end, 103 mesoscale convective systems, 99 of which met MCC criteria, were selected for study. The events occurred during the fouryear period 1980-83 and were identified from the annual MCC summaries of Maddox et al. (1982) and Rodgers et al. (1983) and from inspection of geostationary satellite imagery. Standard surface and upperair sounding data along with hourly manually digitized radar (MDR) composite charts were compiled for each event.

Because the standard sounding data are available only at 0000 and 1200 UTC, criteria had to be established for selecting the time most representative of the MBE environment. Also, since the point of this paper is to develop a tool that will aid in forecasting, it is of most interest to examine whether or not knowledge of $V_{\mathrm{CL}}$ and $V_{\mathrm{LLJ}}$ near the time of MCC genesis is sufficient to produce a successful short-term forecast. Therefore, the sounding time within six hours of MCC genesis, as defined by Maddox (1980), was selected as representative of the MBE environment.

As indicated in (1), a forecast of $V_{\mathrm{MBE}}$ requires estimates of the mean flow in the cloud layer and the lowlevel jet. Based upon the analyses of Maddox (1983) and McAnelly and Cotton (1986), it is assumed that the cloud layer is well represented by the $850-300-\mathrm{mb}$ layer. The mean flow in this layer is determined in a manner following Fankhauser (1964); that is,

$$
V_{\mathrm{CL}}=\frac{V_{850}+V_{700}+V_{500}+V_{300}}{4},
$$

where the direction and magnitude of the wind at each level on the right-hand side is taken to be representative of the 900-800-, 800-600-, 600-400-, and 400-200mb layers, respectively. Fankhauser justified allocating equal weight to the lowest layer despite its smaller depth by noting that most of the air entering a thunderstorm originates at low levels. Estimates of the winds in the vicinity of the MCCs were obtained using the objective analysis system documented in Cahir et al. (1981).

Estimates for the speed and direction of the low-level jet are obtained following the strict criteria of Bonner (1968):

- Criterion 1. The wind speed at the level of maximum wind is $>12 \mathrm{~m} \mathrm{~s}^{-1}$ and decreases by at least 6 $\mathrm{m} \mathrm{s}^{-1}$ to the next higher minimum or the $3-\mathrm{km}$ level, whichever is lower.

- Criterion 2. The wind speed at the level of maximum wind is $>16 \mathrm{~m} \mathrm{~s}^{-1}$ and decreases by at least 8 $\mathrm{m} \mathrm{s}^{-1}$ to the next higher minimum or the $3-\mathrm{km}$ level, whichever is lower.

- Criterion 3. The wind speed at the level of maximum wind is $>20 \mathrm{~m} \mathrm{~s}^{-1}$ and decreases by at least 10 $\mathrm{m} \mathrm{s}^{-1}$ to the next higher minimum or the $3-\mathrm{km}$ level, whichever is lower.

Only wind maxima at or below $1.5 \mathrm{~km}$ above ground level were considered low-level jets since the thunderstorm cells of developing MCCs are most likely to ingest air from near the surface. However, for five cases where pre-MCC convection formed in the overrunning zone above a frontal surface, data from the 2.5- or 3.0$\mathrm{km}$ level were used. In the absence of a low-level maximum in the vertical distribution of the wind, the inflow wind at $850 \mathrm{mb}$ (or at $700 \mathrm{mb}$ over the elevated area between the Rockies and $100^{\circ} \mathrm{W}$ ) that exhibits a maximum in the horizontal wind speed distribution is used as the low-level jet.

Once values for $V_{\mathrm{CL}}$ and $V_{\mathrm{LLJ}}$ are determined, a forecast of the magnitude of $V_{\mathrm{MBE}}$ can be obtained from

$$
\begin{aligned}
\left|V_{\mathrm{MBE}}\right|=\left[\left|V_{\mathrm{CL}}\right|^{2}+\left|-V_{\mathrm{LLJ}}\right|^{2}\right. \\
\left.2\left(\left|V_{\mathrm{CL}}\right| \cdot\left|-V_{\mathrm{LLJ}}\right|\right) \cos \phi\right]^{1 / 2}
\end{aligned}
$$


where $\phi$ is the angle between the mean cloud-layer wind and the low-level jet (see Fig. 1). Similarly, MBE direction can be determined using an elementary relationship for the angle $\varphi$ between the direction of MBE movement and the mean cloud-layer wind:

$$
\varphi=\arcsin \left(\frac{\left|-V_{\mathrm{LLJ}}\right| \cdot \sin \phi}{\left|V_{\mathrm{MBE}}\right|}\right),
$$

where MBE speed is given by (3).

The final set of data necessary to examine whether or not there are useful predictive relationships among $V_{\mathrm{CL}}$, $V_{\mathrm{LLJ}}$, and MBE movement is the observed movement of the MBEs. The MBEs were defined as areas of VIP (video integrator and processor) level 3 or greater on the manually digitized radar (MDR) charts. A VIP value of 3 or more implies an hourly precipitation rate in excess of $25.4 \mathrm{~mm}$ (generally thunderstorm precipitation). Their movement was determined by plotting the centroid of their hourly positions throughout the life cycle of each MCC. A mean speed and direction of MBE movement was determined by subjectively constructing a straight line of best fit from the beginning to the end of each event. Because precipitation intensity is digitized on a grid with only one VIP value allotted for each approximately 40 $\mathrm{km} \times 40 \mathrm{~km}$ area, the resolution of areal intensity is compromised. Such resolution problems are lessened somewhat since the positions and movements of the deepest cells are noted as part of the MDR summary. Additionally, detailed precipitation analyses of all 1982-83 MCCs (available from Kane et al. 1987), using hourly rain gauge data, were examined to corroborate the MDR data; that is, the heaviest precipitation was found to be collocated in general with the MBEs.

\section{Results}

The first step in developing the forecasting technique was to investigate whether or not the advective component of MBE movement, defined as the mean motion of the cells composing the system, is proportional to the mean flow in the cloud layer. Figure 2 presents scatter plots of (a) observed cell speeds versus the magnitude of $V_{\mathrm{CL}}$ and (b) observed cell directions versus the direction of $V_{\mathrm{CL}}$. These plots clearly indicate that much of the cell motion is dictated by the mean cloud layer flow. These results agree with the early radar studies of Brooks (1946) and Byers and Braham (1949), who found that cells move downwind in the direction of the mean cloud layer flow.

A substantially more questionable part of the forecast technique is whether or not the speed and direction of the low-level jet are indicative of the propagation component of MBE movement. If true, this would be a rather sweeping relationship since propagation can be influenced by many factors such as convective available potential energy, convective inhibition, orographic influences, gravity waves, outflow boundaries, etc.
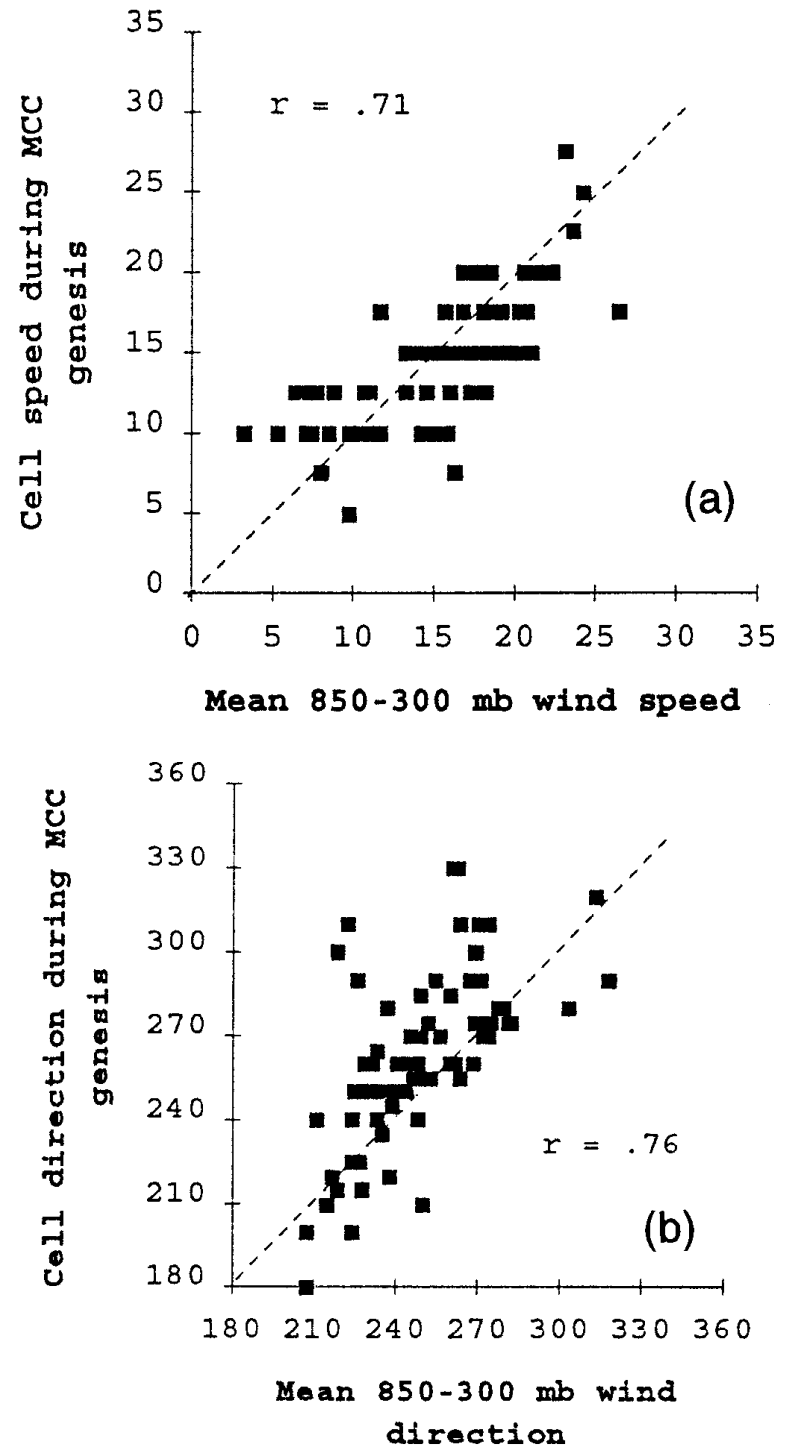

FIG. 2. Scatterplot of (a) mean $850-300-\mathrm{mb}$ wind speed versus cell speed and (b) mean wind direction versus cell direction. Speeds rounded to the nearest $2.5 \mathrm{~m} \mathrm{~s}^{-1}$ and directions to the nearest $5^{\circ}$. Cell movements were available for 74 of the 103 events during the MCC genesis stage. Dashed lines denote a perfect (one to one) relationship.

To examine this issue, we have plotted the direction of the observed propagation component versus the direction of the low-level jet (Fig. 3). The observed propagation component is defined as the departure of the MBE movement from the mean flow in the cloud layer. Clearly, there is a strong tendency for the propagation direction to be approximately $180^{\circ}$ out of phase with the direction of the corresponding low-level jet. Although the correlation coefficient is only 0.65 , this value increases to 0.84 upon omission of the two outliers in the upper-left part of the graph. Thus, in spite of all the factors that influence propagation, it is evident 


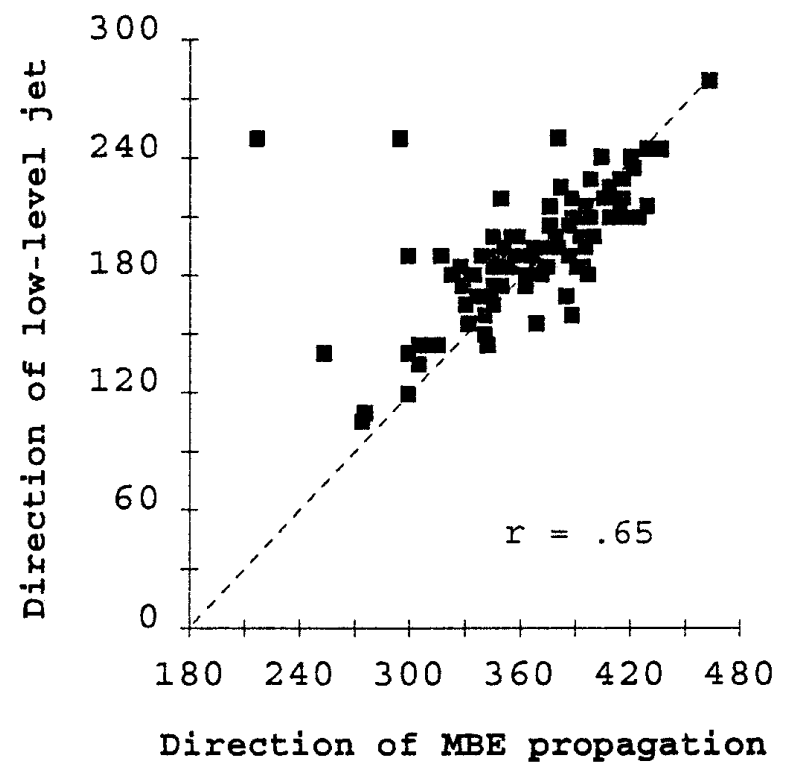

FIG. 3. Scatterplot of MBE propagation direction versus the direction of the low-level jet for 103 events. Propagation direction defined as the layer $(850-300 \mathrm{mb})$ wind. Systems with propagation vectors between $0^{\circ}$ and $120^{\circ}$ have been plotted between 360 and 480. Directions in degrees azimuth. Dashed line denotes perfect antiparallel relationship between direction of MBE propagation and that of the low-level jet.

that there is an overwhelming tendency for MBEs to propagate toward or "into" the low-level jet.

The final component of the conceptual model that needs to be investigated is whether or not the speed of the low-level jet is an important factor in determining the magnitude of $V_{\mathrm{PROP}}$. If this is the case, then it should be true in most cases that the difference between $V_{\mathrm{LLJ}}$ and $V_{\mathrm{CL}}$ will provide a skillful forecast of $V_{\mathrm{MBE}}$, the vector movement of the mesobeta-scale elements.

Figure 4 shows plots of the "forecast" MBE speed and direction versus the observed values; Table 1 summarizes the forecast errors. It is evident that the forecasting technique possesses considerable skill; correlation coefficients are 0.80 and 0.78 for $\mathrm{MBE}$ speed and direction, respectively. The scheme tends to overforecast the speed of slow systems (those with speeds $<12.5 \mathrm{~m} \mathrm{~s}^{-1}$ ) but, overall, provides a good estimate of the rate of movement.

Directional forecasts, however, are somewhat more problematic. Considering that the typical MCC in the United States persists for about $9.5 \mathrm{~h}$ (Velasco and Fritsch 1987), the average directional error shown in Table 1 would result in a $100-150-\mathrm{km}$ error in the location of the center of the MBE activity at the time the system dissipates. Nevertheless, for most of the system's life cycle, the typical location error would be less than $100 \mathrm{~km}$, which is well within the approximately $300-\mathrm{km}$ width of the heavy rainband $(>13 \mathrm{~mm})$ of most MCCs (Kane et al. 1987).

\section{Summary and concluding remarks}

A procedure for operationally predicting the movement of the MBEs responsible for the heavy rain in most MCCs was developed. The procedure is based on the well-known concept that the motion of convective systems can be considered the sum of an advective component, given by the mean motion of the cells composing the system, and a propagation component, defined by the rate and location of new cell formation relative to existing cells. The advective component was found to be correlated to the mean flow in the cloud layer. The propagation component was shown to be
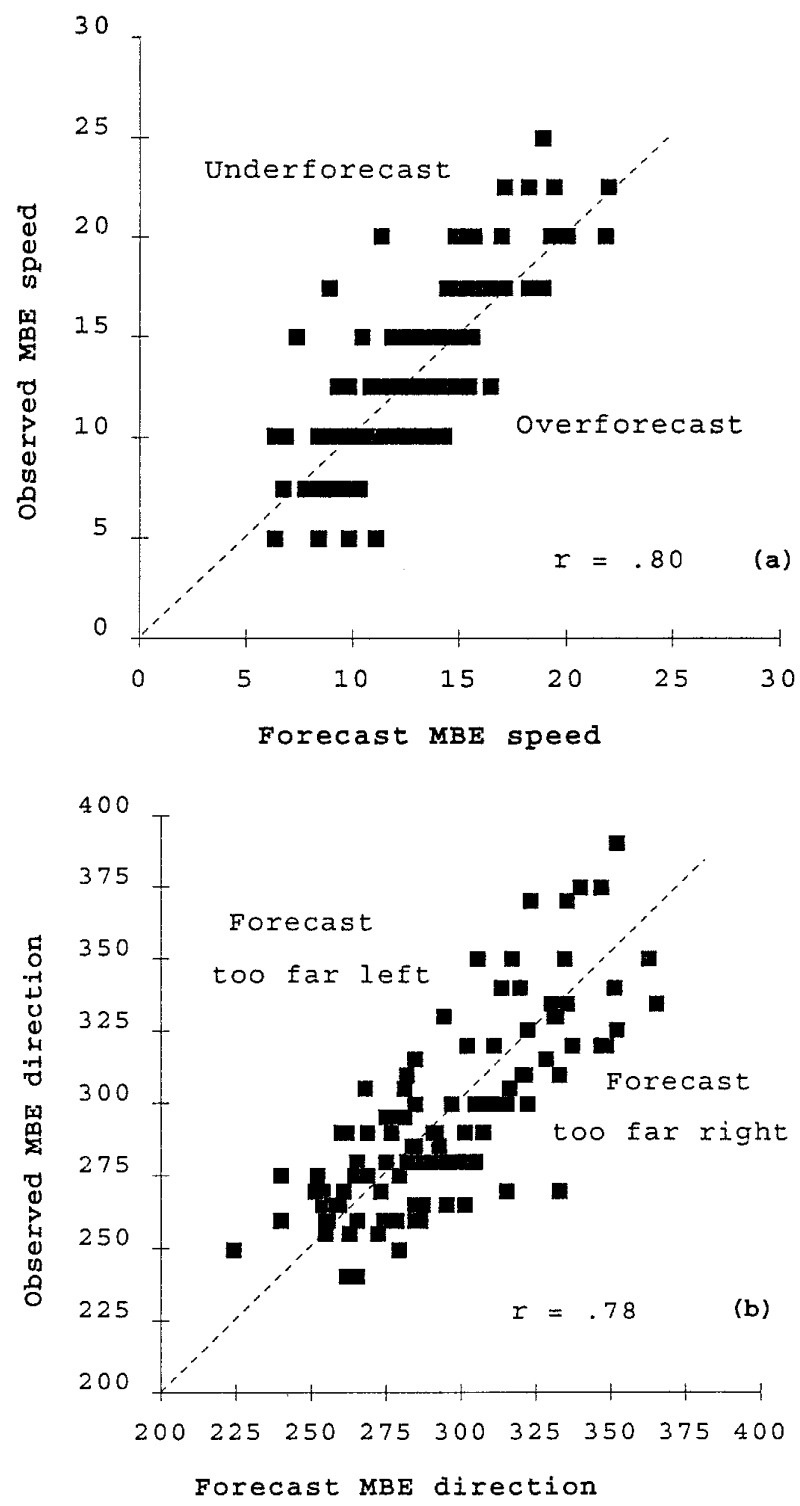

FIG. 4. Scatterplot of (a) forecast MBE speed versus observed and (b) forecast MBE direction versus observed for 103 events. Speeds are rounded to the nearest $2.5 \mathrm{~m} \mathrm{~s}^{-1}$; directions are rounded to the nearest $5^{\circ}$ azimuth. Dashed lines denote perfect forecasts. 
TABLE 1. Comparison of forecast MBE speed and direction to the observed values. Speeds are in $\mathrm{m} \mathrm{s}^{-1}$; directions are in degrees azimuth. Standard deviations are in parentheses. Average absolute error is the sum of the absolute variance for all events divided by the total number of events.

Mean MBE speed
Observed

Forecast by vector approach

Average absolute error

Correlation coefficient (r)

Mean MBE direction

Observed

Forecast by vector approach

Average absolute error

Correlation coefficient (r)
$13.6(4.7)$

$13.0(3.5)$

$+2.0(1.8)$ directly proportional (but opposite in sign) to the speed and direction of the low-level jet.

Application of the procedure to 103 mesoscale convective systems ( 99 of which were MCCs) yielded correlation coefficients of 0.80 and 0.78 for predictions of the speed and direction, respectively, of the MBEs. Mean absolute errors in forecasts of MBE speed and direction were $2.0 \mathrm{~m} \mathrm{~s}^{-1}$ and $17^{\circ}$. For the typical MCC, these errors are sufficiently small so that the forecast path of the center of the MBE activity would be well within the heavy rain swath during most of a given system's life cycle.

The forecast procedure has several advantages that make it well suited to operational use: 1) it requires knowledge only of the speed and direction of the mean cloud-layer wind and the low-level jet, 2) the procedure can be used with all types of environmental wind configurations, and 3) it is capable of "recognizing" quasi-stationary or upstream-propagating systems that are known for producing extremely heavy rainfalls.

Finally, it is important to note that these results, while encouraging, are built upon radar and sounding observations that, by today's standards, are relatively crude. Thus, they should be considered preliminary and subject to validation with more detailed data and/or rigorous operational application. Of course, as the resolution of operational numerical models increases, the formation and movement of MCCs eventually will be predicted explicitly. Thus, forecasting procedures such as the one presented here will be replaced by explicitly predicted MCC paths. In the meantime, however, this procedure can provide quick and useful guidance for improving short-term quantitative precipitation forecasts.

Acknowledgments. Sincere appreciation is extended to George Young, who provided many helpful suggestions and often lent a helping hand. Special thanks are reserved for Harry Henderson for his willing and able computer-related support, and for Dennis Rodgers and
Rod Scofield for their help in acquiring the necessary satellite imagery. Thanks also go to Joann Singer and Delores Corman for providing able technical support.

The authors wish to especially acknowledge Louis Uccellini of the National Weather Service Headquarters in Washington, D.C., without whose support this study would not have been completed. The first author would also like to express appreciation to David A. Olson, Ronald D. McPherson, James Howcroft, and his National Meteorological Center colleagues for allowing him to pursue full-time graduate study at The Pennsylvania State University.

This research was supported by NSF Grant ATM92-22017.

\section{REFERENCES}

Bonner, W. J., 1968: Climatology of the low-level jet. Mon. Wea. Rev., 96, 833-850.

Brooks, H. B., 1946: A summary of some radar thunderstorm observations. Bull. Amer. Meteor. Soc., 27, 557-563.

Byers, H. R., and R. R. Braham Jr., 1949: The Thunderstorm. U.S. Government Printing Office, 287 pp.

Cahir, J. J., J. M. Norman, and D. A. Lowry, 1981: Use of a real time computer graphics system in analysis and forecasting. Mon. Wea. Rev., 109, 485-500.

Chappell, C. F., 1986: Quasi-stationary convectieve events. Mesoscale Meteorology and Forecasting, P. S. Ray, Ed., Amer. Meteor. Soc., 289-310.

Fankhauser, J. C., 1964: On the motion and predictability of convective systems. NSSP Rep. 21, 34 pp.

Fritsch, J. M., and R. A. Maddox, 1981: Convectively driven mesoscale weather systems aloft. Part I: Observations. J. Appl. Meteor., 20, 9-19.

_ R. J. Kane, and C. R. Chelius, 1986: Contribution of mesoscale convective weather systems to the warm season precipitation in the United States. J. Appl. Meteor., 25, 1333-1345.

Funk, T. W., 1991: Forecasting techniques utilized by the Forecast Branch of the National Meteorological Center during a major convective rainfall event. Wea. Forecasting, 6, 548-564.

Heideman, K. F., and J. M. Fritsch, 1988: Forcing mechanisms and other characteristics of significant summertime precipitation. Wea. Forecasting, 3, 115-130.

Jiang, W., and R. A. Scofield, 1987: Satellite observed mesoscale convective system propagation characteristics and a 3-12 hour heavy precipitation forecast index. NOAA Tech. Memo., NESDIS 20, Washington, DC, 43 pp.

Junker, N. W., J. E. Hoke, B. E. Sullivan, K. F. Drill, and F. J. Hughes, 1992: Seasonal and geographic variations in quantitative precipitation prediction by the Nested Grid Model and Medium Range Forecast Model. Wea. Forecasting, 7, 410-429.

Kane, R. J., C. R. Chelius, and J. M. Fritsch, 1987: Precipitation characteristics of mesoscale convective weather systems. J. Climate Appl. Meteor., 26, 1345-1357.

Maddox, R. A., 1980: Mesoscale convective complexes. Bull. Amer. Meteor. Soc., 61, 1374-1387.

__, 1983: Large-scale meteorological conditions associated with midlatitude, mesoscale convective complexes. Mon. Wea. Rev., 111, 1475-1493.

_ D. J. Perkey, and J. M. Fritsch, 1981: Evolution of upper tropospheric features during the development of a mesoscale convective complex. J. Atmos. Sci., 38, 1664-1674.

, D. M. Rodgers, and K. W. Howard, 1982: Mesoscale convective complexes over the United States during 1981-Annual summary. Mon. Wea. Rev., 110, 1501-1514.

— K. W. Howard, D. L. Bartels, and D. M. Rodgers, 1986: Mesoscale convective complexes in the middle latitudes. Mesoscale 
Meteorology and Forecasting, P. S. Ray, Ed., Amer. Meteor. Soc., 390-413.

McAnelly, R. L., and W. R. Cotton, 1986: Meso-betascale characteristics of an episode of meso-alpha-scale convective complexes. Mon. Wea. Rev., 114, 17401770.

Newton, C. W., and S. Katz, 1958: Movement of large convective rainstorms in relation to winds aloft. Bull. Amer. Meteor. Soc., 39, 129-136.

— , and H. R. Newton, 1959: Dynamical interactions between large convective clouds and environment with vertical shear. J. Meteor., 16, 483-496.
Olson, D. A., N. W. Junker, and B. Korty, 1995: Evaluation of 33 years of quantitative precipitation forecasting at the NMC. Wea. Forecasting, 10, 498-511.

Orlanski, I., 1975: A rational subdivision of scales for atmospheric processes. Bull. Amer. Meteor. Soc., 56, 527-530.

Ramage, C. S., 1982: Have precipitation forecasts improved? Bull. Amer. Meteor. Soc., 63, 739-743.

Rodgers, D. M., K. W. Howard, and E. C. Johnston, 1983: Mesoscale convective complexes over the United States during 1982 - Annual summary. Mon. Wea. Rev., 111, 2363-2369.

Velasco, I., and J. M. Fritsch, 1987: Mesoscale convective complexes in the Americas. J. Geophys. Res., 92, 9591-9613. 